\title{
The morphology of the cibarial armature and sensilla of Mansonia titillans, Psorophora cingulata, Coquillettidia arribalzagae, Culex coronator and Limatus durhamii (Diptera: Culicidae)
}

\author{
Sandra Boza ${ }^{1} \&$ Mario Vargas ${ }^{2}$ \\ 1 CIHATA, University of Costa Rica, 2060, San José, Costa Rica; sandraboza.cr@yahoo.es \\ 2 Department of Parasitology, School of Microbiology, University of Costa Rica, 2060 San José, Costa Rica; abetovr@ \\ racsa.co.cr
}

Received 16-IX-2005. C Corrected 08-II-2006. $\quad$ Accepted 23-V-2006.

\begin{abstract}
A detailed description of the cibarial armature of the Neotropical mosquitoes Mansonia titillans, Psorophora cingulata, Coquillettidia arribalzagae, Culex coronator and Limatus durhamii, is presented. A sample of 15 specimens of each species was taken from the collections of two mosquito ecological projects located at Santa Clara, San Carlos, Alajuela and from La Selva, Sarapiquí, Heredia, Costa Rica. Each specimen, preserved in alcohol, was cleared, put into a mounting medium, head separated from body and eyes pinched to expose the cibarial armature and sense organs; finally a coverslip was added for a permanent slide. The bodies of all the mosquitoes were also mounted onto slides. The descriptions of the cibarial armatures were based on the characteristics of the dome, body, transversal bar, lateral flanges and cibarial teeth. Also the number, distribution and type of the sense organs are given. From the analysis, and comparison with known descriptions of other neotropical species, we conclude that the five species studied show enough characteristics for species recognition purposes. Rev. Biol. Trop. 54 (3): 815-820. Epub 2006 Sept. 29.
\end{abstract}

Key words: Neotropics, mosquitoes, cibarial armature, sense organs, morphology.

The study of mosquitoes of human and veterinary importance must be a basic approach in an integrated management of vector control, especially in the neotropics. The taxonomy of adult culicids is still based mostly in external characters, size, genitalia and scale patterns. This is especially true for females. However, some collecting techniques, preservation methods and time, result in deterioration of important characters employed in taxonomic keys. For such reasons the classical study of the external and internal morphology is still needed in the recognition of the disease vectors.

The use of internal structures in insect taxonomy is not new. In some groups of dipterans the cibarium shows valuable characteristics that serve to separate species (i.e. phlebotomines). The morphology of the cibarial armature (CA) is useful not only for taxonomic purposes but for the interpretation of possible affinities among genera and also for host-parasite relationships of epidemiological value (McGreevy et al.1978).

In mosquitoes the use of the CA in taxonomy has been limited to a few studies, basically those of Sinton and Covell (1927), Barraud and Covell (1928), Lane (1953), Valencia (1973), Lee (1974), Sirivanakarn (1978), and Lee and Craig (1983). Few authors, such as Lane (1953), Valencia (1973), Sirivanakarn (1978), have described or figured the CA of neotropical culicine species reported from Costa Rica. Lane (1953) described and figured the CA (which he called bucco-pharyngeal) armature of Culex (Lu.) bigoti, Culex (Cx.) pipiens fatigans and Culex (Car.) urichii. Valencia (1973) made a revision of the subgenus Carrollia of Culex. This author included figures of the Costa 
Rican species Culex (Car.) bihaicolus, Cx. metempsytus, $C x$. urichii, Cx. secundus, $C x$. babahoyensis, and $C x$. antunesi. Sirivanakarn (1978) made an attempt to classify species on the basis of similarity in the CA. For example, for the subgenus Melanoconion he recognized five different types and five subtypes based on the number of the cibarial teeth and their shape and size. Also he followed the same criteria to consider three types and two subtypes of CA in Microculex. The author concluded that in the subgenera Aedinus, Anoedioporpa, Belkinomyia, Carrollia, Micraedes, Tinolestes and in the majority of species of Microculex, the CA is very characteristic and provides an important character at subgeneric level.

In his comparative study of New World subgenera of Culex, Sirivanakarn included the following species from Costa Rica: Culex (Mel.) bastagarius, Cx. conspirator, Cx. educator, Cx. elevator, Cx. erraticus, $C x$. inhibitator, $C x$. iolambdis, $C x$. pilosus and Cx. trifidus. In the subgenus Carrollia, Cx. (Car.) metempsytus. From Microculex to $C x$. (Mic.) jenningsi, $C x$. rejector and $C x$. restrictor. From $C x$. Tinolestes to $C x$. (Tin.) latisquama. From Lutzia to $C x$. (Lu.) allostigma. From Culex to $C x$. (Cx.) coronator, Cx. declarator and $C x$. nigripalpus. From Neoculex to Cx. (Neo.) derivator and finally from the genus Deinocerites to Deinocerites cancer.

Lee and Craig (1983) made a detailed study of the cibarial sense organs: palatal papillae (pp), campaniform sensilla (cs), dorsal papillae (dp), trichoid sensilla (trs) and ventral papillae (vp). These authors showed that in the 37 species studied, representing nine genera, the number of campaniform sensilla and dorsal papillae is constant (two). Also four ventral papillae are present for all species except for one with two and another without such papillae.

The number of trichoid sensillae ranged from two to ten. An interesting fact is that the palatal sensilla divided species into two groups, one with four and the other with six. In regards to the cibarial teeth, the author found that such structures were not present in the genera Culiseta, Armigeres, Aedes, Psorophora, Coquillettidia and in some species of Anopheles.
Finally the mentioned authors included seven species of mosquitoes found in Costa Rica, Anopheles (Nys.) albimanus, Psorophora (Jan.) ferox, Ps. (Jan.) varipes, Aedes (Steg.) aegypti, Culex (Cx.) declarator, Cx. (CX.) pipiens fatigans, and Culex (Mel.) erraticus.

\section{MATERIALS AND METHODS}

Female mosquitoes were collected in 1982-1984 from two monitoring projects, and preserved in alcohol from the locality of Santa Clara, San Carlos, Alajuela and from La Selva, Sarapiquí, Heredia. $\left(10^{\circ} 00-10^{\circ} 30^{\prime} \mathrm{N}, 8^{\circ} 00\right.$ $84^{\circ} 30^{\prime} \mathrm{W}$ ). The observations were based on samples of 15 females of each species previously identified as Mansonia titillans (Walker, 1848), Psorophora cingulata, (Fabricius, 1805), Coquillettidia arribalzagae (Theobald, 1903), Culex coronator Dyar and Knab, 1906 and Limatus durhamii Theobald, 1901. All females were identified following the keys by Darsie (1993). Specimens are deposited at the Museum of Zoology, School of Biology, University of Costa Rica.

The specimens were placed separately into small plates with Nesbitt's solution and kept for two days for complete clearing. After clearing, each specimen was placed on a microscope slide in a drop of Hoyer's mounting medium. The head was separated from the body and then placed onto another slide in a drop of Hoyer's for dissection of the mouth parts, antennae, and palps. Finally the compound eyes were pinched with minuten needles in order to expose the CA located immediately behind the clypeus. The dissected parts (head and body) of each specimen were covered with round coverslips, kept at $37^{\circ} \mathrm{C}$ for a week and sealed and identified with a corresponding code.

The morphological comparative study of the five mentioned species was based on the following structures: dome, cibarial body, transversal bar, lateral flanges, cibarial teeth and sensilla. The measurements made were the length of the cibarial body, maximal width of the cibarial body, length of the lateral flanges and distance between the lateral flanges. 


\section{RESULTS \\ Mansonia titillans (Fig. 1)}

Dome: very reduced. With microsetae ending in small points. Cibarial body: with very sclerotised margins. Anterior hard palate: Dark brown, elongated, with irregular margins. About 90 x $36 \mu \mathrm{m}$. Posterior hard palate: Dark brown. Elongated. About 90 x 30 $\mu \mathrm{m}$. Lateral flanges: Very sclerotised. Strong and with a sub-distal inner salient and two small spicules. Transversal bar: Inner margin smooth. Cibarial teeth: Not present. Sensilla: With $1+1$ dorsal papillae (dp), $2+2$ ventral papillae (vp), 3+3 sensilla trichoides (str), 1+1 campaniform sensilla (cs), $2+2$ palatal papillae (pp). Measurements: Length of cibarial body, $260 \mu \mathrm{m}$. Width of cibarial body: 130 $\mu \mathrm{m}$. Length of lateral flanges: $80 \mu \mathrm{m}$. Distance between the lateral flanges: $160 \mu \mathrm{m}$.

\section{Psorophora cingulata (Fig. 2)}

Dome: Very reduced. Cibarial body: With moderately sclerotised margins. Anterior hard palate: Somewhat rectangular. Strongly corrugated. Posterior hard palate: Short. Elongated. Lateral flanges: Sclerotised. Very short. Strong. Recurved and ending in an expanded wing not sclerotised. Transversal bar: Anterior border smooth, convex and strongly sclerotised. Cibarial teeth: There are two types of teeth distributed in two groups, placed in a very sclerotised area. One group is placed laterally, very numerous, conical, with a wide base and hollows looking as very strong spines ending in several points. The second group is located medially and forms a part of the bar and is closely packed. Sensilla: 1+1 dp, 2+2 vp, 5+5 str, 1+1 cs, 2+2 pp. Measurements: Length of cibarial body: 300 $\mu \mathrm{m}$. Width of cibarial body: $160 \mu \mathrm{m}$. Length of lateral flanges: $60 \mu \mathrm{m}$. Distance between lateral flanges: $160 \mu \mathrm{m}$.



Fig. 1. Mansonia titillans.

\section{Coquillettidia arribalzagae (Fig. 3)}

Dome: Well developed. With triangular denticles. Slightly flattened. Cibarial body: Very strongly sclerotised, especially towards the lateral flanges. Anterior hard palate: With posterior and squamous and half-moon shaped. Posterior hard palate: Not very well defined except at the border of the bar that shows a series of small excrescences. Lateral flanges: Dilated at the distal end, forming a plate and with a medial concavity that serves to allocate the cibarial teeth. Tranversal bar: Anterior border almost straight. Cibarial teeth: Laterally placed in a concavity of the lateral flanges. Teeth of different sizes and shapes. A peculiar distribution of the teeth: $2+2$ basal, 1+1 towards the medial line, distal teeth with multiple points or brush-tipped, a central 


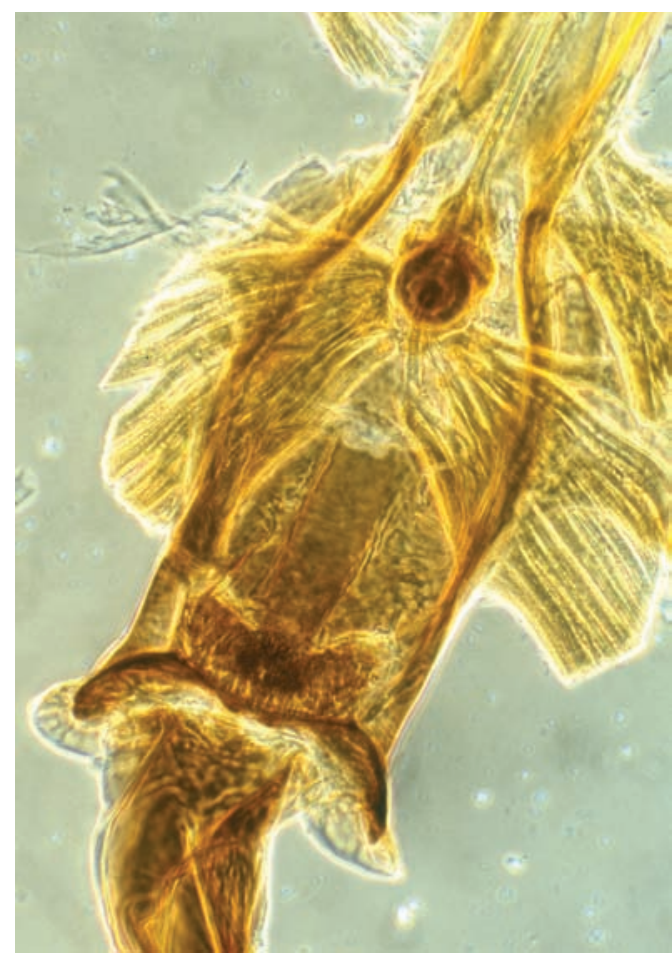

Fig. 2. Psorophora cingulata.

enlarged monticle of teeth with multiple tips, a concavity with four irregular teeth. Sensilla: 1+1 dp, 0+0 vp, 2+2 str, 1+1 cs, 3+3 pp. Measurements: Length of cibarial body: 235 $\mu \mathrm{m}$. Width of cibarial body: $120 \mu \mathrm{m}$. Length of lateral flanges: $70 \mu \mathrm{m}$. Distance between lateral flanges: $160 \mu \mathrm{m}$.

\section{Culex (Cx.) coronator (Fig. 4)}

Dome: Well developed. A central lobe and lateral lobes. Slightly flattened. Constituted by many triangular scales looking backwards. Cibarial body: Tubuliform. Strongly sclerotised. Anterior hard palate: Sclerotised elongated plate. Posterior hard palate: Slightly sclerotised. Ovoid. Lateral flanges: Short, slightly arched. Slightly sclerotised. Transversal bar: Poorly sclerotised. Posterior border almost straight. Cibarial teeth: Distributed in a single line. Twenty teeth with well inserted wide bases and pointed apices. Sensilla: $1+1 \mathrm{dp}, 1+1 \mathrm{cs}, 2+2$ trs, $2+2$ vp, 2+2 pp. Measurements: Length of cibarial

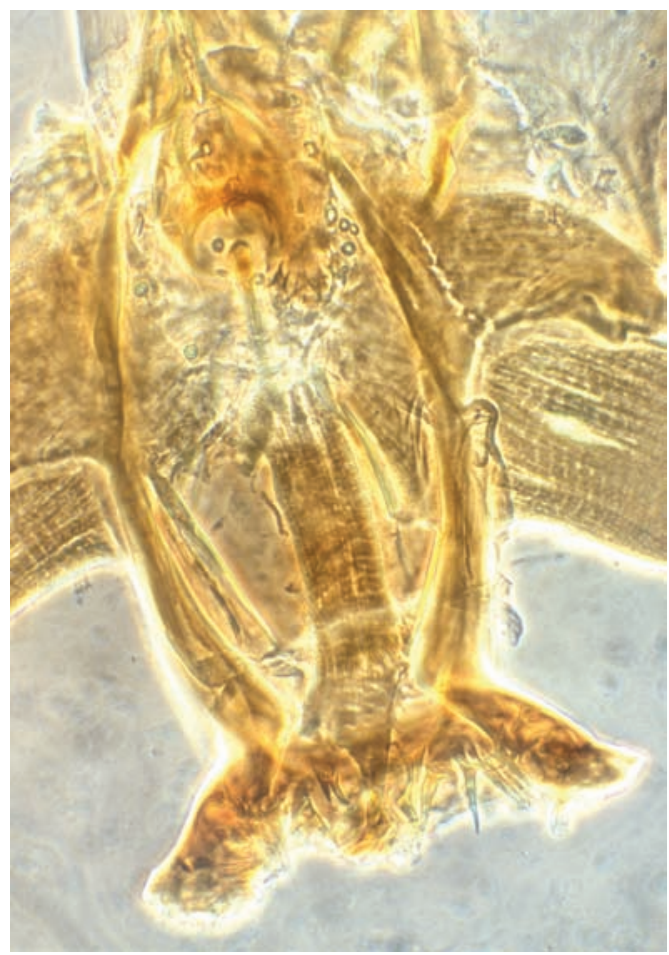

Fig. 3. Coquillettidia arribalzagae.



Fig. 4. Culex (Cx.) coronator. 
body: $198 \mu \mathrm{m}$. Width of cibarial body: 108 $\mu \mathrm{m}$. Length of lateral flanges: $65 \mu \mathrm{m}$. Distance between lateral flanges: $90 \mu \mathrm{m}$.

\section{Limatus durhamii (Fig. 5)}

Dome: Not present. Cibarial body: Moderately sclerotised. Lateral margins straight, parallel. Anterior hard palate: Sclerotised, fusiform. With irregular borders. Posterior hard palate: Slightly sclerotised, rectangular, spiny towards its base and striated towards the transversal bar. Lateral flanges: Short and strong, looking outwards. Transversal bar: Sclerotised. Posterior border smooth. With two papillae. Cibarial teeth: Not present. Sensilla: 1+1 dp, 1+1 vp, 1+1 cs, 2+2 str, 2+2 pp. Measurements: Length of cibarial body: 206 $\mu \mathrm{m}$. Width of cibarial body: $70.6 \mu \mathrm{m}$. Length of lateral flanges: $32.0 \mu \mathrm{m}$. Distance between lateral flanges: $88 \mu \mathrm{m}$.



Fig. 5. Limatus durhamii.

\section{DISCUSSION}

Based on the structure of the CA, the five species of mosquitoes we have studied from Costa Rica (Mansonia titillans, Psorophora cingulata, Coquillettidia arribalzagae, Culex coronator and Limatus durhamii) might be distinguished by the following characters:

The CA in Mansonia species has not been studied previously. Ma. titillans does not have cibarial teeth, but the sensory organs, their number, type and distribution are typical (Fig. 1). The CA in Psorophora is described for two species, Ps. (Jan.) ferox and Ps. (Jan.) varipes (Lee and Craig 1983), both of which have the sense organ formula 4 pp, 2 cs, 2 dp, 8 and 6-8 str, $4 \mathrm{vv}$ and both lack cibarial teeth. In contrast, Ps. cingulata (Fig. 2) has the formula 4 pp, 2 cs, 2 dp, 10 trs, 4 vv, and the cibarial teeth are distributed in two groups, a character that separates this species from ferox and varipes.

The CA of the genus Coquillettidia has been described only for Coquillettidia perturbans (Lee and Craig, 1983). These authors give the following sense organ formula: $6 \mathrm{pp}, 2 \mathrm{cs}$, 2 dp, 6 trs, 4 vp and no cibarial teeth. In contrast, Coq. arribalzagae (Fig. 3) has the sense organ formula: 6 pp, 2 cs, 2 dp, 4 str, 0 vp and the cibarial teeth (contrary to the statement of Lane and Craig, 1983) distributed in a pattern of $2+2$ basals, $1+1$ towards the median line and with a central promontory with teeth ending in multiple points.

The CA of Culex (Cx.) coronator is included by Sirivanakarn (1978) as one of the species studied by him, but it is not described nor figured. The author only mentioned that in the subgenus Culex the dome is small, poorly sclerotised, the transversal bar is broad and the cibarial teeth vary from 20 to 30; these teeth are short or moderately long, deeply rooted with abruptly pointed apices. In $C x$. (Cx.) coronator (Fig. 4) the dome is flat, with a central monticle. The cibarial body shows sclerotised borders. The anterior hard palate is slender, with four spines and the posterior is irregular. The transversal bar includes 24 very small teeth. The sense organ formula is: $2+2 \mathrm{pp}, 1+1 \mathrm{cs}, 1+1$ dp, $2+2$ str, $2+2$ vp. The measurements might 
be of value to separate this species from others of this subgenus. This aspect needs future comparative studies.

We could find no description of the CA for any Limatus species (Fig. 5) in the literature. Future descriptions of other species will be necessary to determine comparative differences of these structures.

Of the 208 species of mosquitoes recorded in Costa Rica by Vargas (1998) the CA has been described or figured for about 33. To these we add the CA of five more CA for neotropical female mosquitoes not previously described.

We consider that the CA, as shown by Sirivanakarn (1948), is important for the study of taxonomy, evolutionary relationships and disease epidemiology among mosquitoes, and stress the necessity of increasing this field of research to provide a better understanding of the biology of these disease vectors.

\section{ACKNOWLEDGMENTS}

We thank N. Medappa, Editor of the Indian J. Med. Res., for important references on the subject, and W. Bussing (University of Costa Rica), Richard D. Darsie Jr. (Florida Medical Entomology Laboratory) and one anonymous referee for revision of the English text.

\section{RESUMEN}

Se presenta una detallada descripción de la armadura cibarial y órganos sensoriales de hembras de mosquitos de cinco especies neotropicales, Mansonia titillans, Psorophora cingulata, Coquillettidia arribalzagae, Culex coronator y Limatus durhamii. Se tomó una muestra de 15 especimenes de cada especie de las colecciones de mosquitos de dos proyectos ecológicos localizados en Santa Clara, San Carlos, Alajuela y de La Selva, Sarapiquí, Heredia, Costa Rica. Los especimenes, preservados en alcohol de $85^{\circ}$, se aclararon en solución de Nesbitt, se disecaron las cabezas y se punzó los ojos compuestos para exponer la armadura cibarial y sus órganos sensoriales. Se utilizó el medio de Hoyer para hacer las preparaciones fijas. Asimismo los cuerpos de los especimenes fueron colocados en el medio de montaje. A todas las preparaciones se les colocó un cubreobjeto. Se utilizó la microscopia de contraste de fases para lograr una mejor apreciación de las estructuras. La descripción de las armaduras cibariales se basó en las características del domo, cuerpo, barra transversal y barras laterales, y dientes cibariales. También se informa el número, distribución y tipo de los órganos sensoriales. Hay diferencias estructurales suficientes para distinguir las cinco especies estudiadas entre sí y de otras especies de la culicidofauna neotropical.

Palabras clave: Neotrópico, mosquitos, armadura cibarial, órganos sensoriales, morfología.

\section{REFERENCES}

Barraud, P.J. \& G. Covell. 1928. The morphology of the buccal cavity in anopheline and culicine mosquitoes. Ind. J. Med. Res. 15: 671-679.

Darsie, R.F.Jr. 1993. Keys to the Mosquitoes of Costa Rica (Diptera: Culicidae). International Center for Disease Control, Univ. South Carolina, South Carolina, USA. 58 p.

Lane, J. 1953. Neotropical Culicidae. Vol 1. Univ. Sao Paulo, Sao Paulo, Brazil. 548 p.

Lee, R. 1974. Structure and function of the fascicular stylets, and the labral and cibarial sense organs of male and female Aedes aegypti (L.) (Diptera: Culicidae). Quaest Entomol. 10: 187-215.

Lee, R.M.K.W. \& D.A. Craig. 1983. Cibarial sensilla and armature in mosquito adults (Diptera: Culicidae). Can. J. Zool. 61: 633-646.

McGreevy, P.B, J.H. Bryan, P. Oothuman \& N. Kolstrup 1978. The lethal effects of the cibarial and pharyngeal armatures of mosquitoes on microfilariae. Trans. R. Soc. Trop. Med. Hyg. 72: 361-367.

Sinton, J.A. \& G. Covell 1927. The relation of the morphology of the buccal cavity to the classification of anopheline mosquitoes. Ind. J. Med. Res. 15: 301-308.

Sirivanakarn, S. 1978. The female cibarial armature of New World Culex, subgenus Melanoconion and related subgenera with notes on this character in subgenera Culex, Lutzia and Neoculex and genera Galindomyia and Deinocerites (Diptera: Culicidae). Mosq. Syst. 10: 474-492.

Valencia, JD. 1973. Mosquito studies (Diptera: Culicidae) XXXI. A revision of the subgenus Carrollia of Culex. Contrib. Am. Entomol. Inst. 9: 1-134.

Vargas, M. 1998. El mosquito: Un enemigo peligroso (Diptera: Culicidae). University of Costa Rica, San José, Costa Rica. 264 p. 